\title{
Jasmonic Acid and Ethylene Signaling Pathways Regulate Glucosinolate Levels in Plants During Rhizobacteria-Induced Systemic Resistance Against a Leaf-Chewing Herbivore
}

\author{
Nurmi Pangesti ${ }^{1}$ Michael Reichelt ${ }^{2}$ - Judith E. van de Mortel $^{3,4}$ • Eleni Kapsomenou ${ }^{1}$. \\ Jonathan Gershenzon ${ }^{2}$ • Joop J. A. van Loon ${ }^{1}$ • Marcel Dicke ${ }^{1}$ • Ana Pineda ${ }^{1,5}$
}

Received: 24 February 2016 /Revised: 18 June 2016 / Accepted: 20 October 2016 /Published online: 15 November 2016

(C) The Author(s) 2016. This article is published with open access at Springerlink.com

\begin{abstract}
Beneficial soil microbes can promote plant growth and induce systemic resistance (ISR) in aboveground tissues against pathogens and herbivorous insects. Despite the increasing interest in microbial-ISR against herbivores, the underlying molecular and chemical mechanisms of this phenomenon remain elusive. Using Arabidopsis thaliana and the rhizobacterium Pseudomonas simiae WCS417r (formerly known as P. fluorescens WCS417r), we here evaluate the role of the JA-regulated MYC2-branch and the JA/ET-regulated ORA59-branch in modulating rhizobacteria-ISR to Mamestra brassicae by combining gene transcriptional, phytochemical, and herbivore performance assays. Our data show a consistent negative effect of rhizobacteria-mediated ISR on the performance of M. brassicae. Functional JA- and ETsignaling pathways are required for this effect, as shown by investigating the knock-out mutants $d d e 2-2$ and ein $2-1$.
\end{abstract}

Electronic supplementary material The online version of this article (doi:10.1007/s10886-016-0787-7) contains supplementary material, which is available to authorized users.

Nurmi Pangesti

npangesti001@gmail.com

1 Laboratory of Entomology, Wageningen University, P.O. Box 16, 6700 AA Wageningen, The Netherlands

2 Department of Biochemistry, Max Planck Institute for Chemical Ecology, 07745 Jena, Germany

3 Laboratory of Phytopathology, Wageningen University, P.O. Box 16, 6700 AA Wageningen, The Netherlands

4 Present address: HAS University of Applied Sciences, 5911 KJ Venlo, The Netherlands

5 Present address: Department of Terrestrial Ecology, Netherlands Institute of Ecology (NIOO-KNAW), PO Box 50, 6700 AB Wageningen, The Netherlands
Additionally, whereas herbivory mainly induces the MYC2branch, rhizobacterial colonization alone or in combination with herbivore infestation induces the ORA59-branch of the JA signaling pathway. Rhizobacterial colonization enhances the synthesis of camalexin and aliphatic glucosinolates (GLS) compared to the control, while it suppresses the herbivoreinduced levels of indole GLS. These changes are associated with modulation of the JA-/ET-signaling pathways. Our data show that the colonization of plant roots by rhizobacteria modulates plant-insect interactions by prioritizing the JA/ETregulated ORA59-branch over the JA-regulated MYC2branch. This study elucidates how microbial plant symbionts can modulate the plant immune system to mount an effective defense response against herbivorous plant attackers.

Keywords Camalexin · Glucosinolates · Induced systemic resistance $\cdot$ Plant growth-promoting rhizobacteria $\cdot$ Signaling pathways

\section{Introduction}

Plants as primary producers in terrestrial ecosystems are exposed to various attackers, with insect herbivores among the most important ones. To survive, plants have evolved physical and chemical barriers as defenses against insect herbivores. Upon recognition of insect elicitors, plants use hormones that regulate signaling pathways to reprogram their transcriptome and metabolome, thus strengthening their defense (Bodenhausen and Reymond 2007; De Vos et al. 2005; Reymond et al. 2004). In Brassicaceous plants, including Arabidopsis thaliana, glucosinolates (GLS) are the main defensive compounds that confer plant resistance against insect herbivores (Beekwilder et al. 2008; Howe and Jander 2008; Mewis et al. 2006; Müller et al. 2010). The two most abundant 
classes of GLS are aliphatic and indolic GLS, depending on whether the side chain is derived from the amino acid methionine or tryptophan, respectively (Halkier and Gershenzon 2006). Feeding by specialist and generalist leaf-chewing insects triggers enhanced synthesis of aliphatic and indolic GLS (Kos et al. 2012; Verhage et al. 2011). More recent studies show that other compounds, such as camalexin, a brassicaceous indolic phytoalexin, also contribute to plant resistance against herbivores (Kettles et al. 2013; Kusnierczyk et al. 2008; Prince et al. 2014; Schlaeppi et al. 2008). Unraveling how plant signaling pathways and crosstalk between pathways regulate the synthesis of defensive compounds in the context of multitrophic interactions has only just begun.

The signaling pathway regulated by the plant hormone jasmonic acid (JA) is the core pathway regulating resistance to leaf-chewing herbivores (Erb et al. 2012; Farmer and Ryan 1992; Howe and Jander 2008; Kessler and Baldwin 2002), through formation of physical barriers such as trichomes and enhanced synthesis of defensive compounds such as GLS (Erb et al. 2012; Howe and Jander 2008). The JA-signaling pathway has two branches that cross-communicate with other hormonal pathways, such as the ethylene (ET) and abscisic acid (ABA) pathways through the use of common transcription factors (Kazan and Manners 2008; Lorenzo and Solano 2005). The transcription factor ORA59 is one of the main integrators of the JA- and ET-signaling pathways (Lorenzo et al. 2003; Pre et al. 2008), whereas transcription factor MYC2 is one of the main integrators of JA- and ABAsignaling pathways (Abe et al. 2002; Vos et al. 2013). Each of these two transcription factors activates different sets of JAresponsive genes (Kazan and Manners 2013; Lorenzo and Solano 2005; Pieterse et al. 2012). In A. thaliana, MYC2 regulates the biosynthesis of defensive compounds such as camalexin and GLS (Kazan and Manners 2013; Schweizer et al. 2013). In line with this, feeding by the leaf-chewing insects Pieris rapae and Helicoverpa armigera induces the MYC2-branch and enhances the expression of the JAresponsive gene Vegetative Storage Protein 2 (VSP2) (Verhage et al. 2011). The MYC2-branch also has an important function in mediating the ability of beneficial microbes to prime plant defenses to pathogens (Pozo et al. 2008). An intriguing question then is whether the MYC2-branch also plays a role in the ability of beneficial microbes to increase plant resistance to insect herbivores.

Plants host a diversity of microbes, including beneficial microbes in the rhizosphere that can affect plant defense and growth. The influence of beneficial microbes on plant defense and growth is mediated by their effect on plant signaling pathways that not only regulate microbial colonization but also trigger significant changes in plant gene expression, metabolism, and physiology (Cartieaux et al. 2008; Van de Mortel et al. 2012; Verhagen et al. 2004; Weston et al. 2012).
Interestingly, several species of root-associated microbes from the genera Pseudomonas, Bacillus, and Trichoderma enhance plant immunity, through a mechanism called induced systemic resistance (ISR), known to inhibit growth and development of various insect herbivores and pathogens (Pangesti et al. 2015; Pineda et al. 2010; Song et al. 2013; Valenzuela-Soto et al. 2010). Intact JA and ET hormonal signaling pathways are required to induce ISR by several root-associated microbes such as $P$. fluorescens WCS417r against pathogens (Pieterse et al. 1998). Based on the whole genome sequence comparison, this rhizobacterium isolate recently has been renamed into Pseudomonas simiae WCS417r (Berendsen et al. 2015). However, it is unknown if intact JA and ET signaling pathways also regulate ISR against insect herbivores. Furthermore, it remains to be elucidated how plants regulate chemical defense against insect herbivores upon colonization by root-associated beneficial microbes.

The present study investigates how colonization by the rhizobacterium $P$. simiae WCS417r affects plant defense against the leaf-chewing insect Mamestra brassicae. Previous studies have found that this rhizobacterium triggers an enhanced expression of the JA-regulated gene $L O X 2$ and the JA/ET-regulated genes PDF1.2 and HEL upon feeding by the generalist caterpillars M. brassicae and Spodoptera exigua (Pangesti et al. 2015; Van Oosten et al. 2008). However, whether the JA-regulated MYC2-branch or the JA/ETregulated ORA59-branch is modulating plant defense in rhizobacteria-mediated ISR against insects is unknown. To investigate this, gene transcription, plant chemistry, and performance of the herbivore $M$. brassicae were analyzed in vitro in wild type $A$. thaliana Col-0 and in mutants defective in the JA pathway, i.e., dde2-2 and myc2, in the ET pathway, i.e., ein 2-1, and in the JA/ET pathway, i.e., ora59. We hypothesized that rhizobacteria-treatment of plants 1) triggers enhanced expression of the JA/ET-regulated genes ORA59 and $P D F 1.2$ and of the JA-regulated genes MYC2 and VSP2 upon feeding by $M$. brassicae, 2) increases the synthesis of glucosinolates and camalexin upon feeding by M. brassicae, and 3) results in stronger resistance to $M$. brassicae via the JA- and ET-signaling pathways.

\section{Methods and Materials}

Rhizobacterium Pseudomonas simiae WCS417r, Growing Conditions, and Quantification The rifampicin-resistant, non-pathogenic epiphyte rhizobacterium strain $P$. simiae WCS417r (abbreviated as PS. WCS417r) was used. Rhizobacteria were grown on King's B (KB) medium agar plates containing rifampicin $\left(25 \mu \mathrm{g} \mathrm{ml}{ }^{-1}\right)$ for $48 \mathrm{~h}$ at $28^{\circ} \mathrm{C}$ (Pieterse et al. 1996). Prior to inoculation on plant roots, a single colony of the strain was transferred to KB liquid medium amended with rifampicin as indicated above, and was 
grown in an incubator shaker for $24 \mathrm{~h}$ at 200 rotations per minute (rpm) at $25^{\circ} \mathrm{C}$. The bacterial cells were collected, resuspended in $10 \mathrm{mM} \mathrm{MgSO}_{4}$, and washed three times with $10 \mathrm{mM} \mathrm{MgSO}_{4}$. Afterwards, the bacterial cells were resuspended in $10 \mathrm{mM} \mathrm{MgSO}_{4}$ and adjusted to a cell density of $1 \times 10^{9}$ colony forming units $(\mathrm{cfu}) \mathrm{ml}^{-1}(\mathrm{OD} 660=1.0)$.

Colonization of $A$. thaliana roots by Ps. WCS417r was quantified in wild type plants and mutants to confirm that the colonization met the required threshold for ISR of $10^{5} \mathrm{cfu}^{-1}$ root (Raaijmakers et al. 1995). The rhizobacteria quantification was done following the method described in Pangesti et al. (2015), with slight modification. Roots were harvested, weighed, and shaken vigorously for $1 \mathrm{~min}$ in $10 \mathrm{ml}$ of $10 \mathrm{mM} \mathrm{MgSO}_{4}$ containing $0.5 \mathrm{~g}$ of glass beads (425-600 $\mu \mathrm{m}$, Sigma-Aldrich). Proper dilutions were plated onto KB agar medium supplemented with $25 \mathrm{\mu g} \mathrm{ml}^{-1}$ rifampicin to select for rifampicinresistant fluorescent Pseudomonas spp. (Pieterse et al. 1998). The dilution plates were incubated for $48 \mathrm{~h}$ at $28^{\circ} \mathrm{C}$, after which the number of cfu per mg root fresh weight was determined.

Mamestra brassicae Rearing The generalist insect herbivore M. brassicae L. (Lepidoptera: Noctuidae; Cabbage moth) was reared on Brassica oleracea L. var. gemmifera cv. Cyrus (Brussels sprouts) in a climate chamber $\left(22 \pm 2{ }^{\circ} \mathrm{C}, 40-50 \%\right.$ $\mathrm{RH}, 16: 8 \mathrm{~h}$ photo:scotophase). Newly-emerged larvae were used in the experiments.

Cultivation of A. thaliana Col-0 in vitro Arabidopsis thaliana Col-0 plants were surface-sterilized and grown in vitro following a method described in Van de Mortel et al. (2012). In this study, A. thaliana Col-0 and mutants defective in the JA signaling pathway (dde2-2, myc2) and in the JA/ET signaling pathway (ein2-1, ora59) were used. Mutant dde2-2 is defective in ALLENE OXIDE SYNTHASE, a key enzyme in the JA-biosynthesis pathway (Von Malek et al. 2002), mutant myc2 is defective in transcription factor MYC2/JIN1 and is activated by the JA-signaling pathway (Hiruma et al. 2011). Mutant ein2-1 is defective in the nuclear protein ETHYLENE INSENSITIVE 2-1, a central component of the ET-signaling pathway (Guzman and Ecker 1990), mutant ora59 is defective in transcription factor ORA59 that is involved in the JA/ETsignaling pathways (Pre et al. 2008). A total of 12 seeds of the same line were sown on square plates $(100 \times 100 \times 20 \mathrm{~mm})$ (SARSTEDT, Nümbrecht, Germany) containing $50 \mathrm{ml}$ of half-strength Murashige and Skoog (MS) medium (Murashige and Skoog 1962), and seeds were incubated for $7 \mathrm{~d}$ in a growth chamber at $21 \pm 2^{\circ} \mathrm{C}, 60 \%$ relative humidity (RH), 16:8 h L:D cycle, and $90 \pm 1 \mu \mathrm{mol} \mathrm{m}^{-2} \mathrm{~s}^{-1}$ light intensity (SYLVANIA, GRO-LUX®, Germany). Seven-d-old plant seedlings were root tip-inoculated with $2 \mu$ of $P S$. WCS417r cell suspension $\left(10^{9} \mathrm{CFU} \mathrm{ml}^{-1}\right)$. For control treatment, plant seedlings were mock-inoculated with $2 \mu \mathrm{l}$ of
$\mathrm{MgSO}_{4}$ solution. After root inoculation, plants were incubated for an additional $7 \mathrm{~d}$ in the same conditions as described above. Fourteen-d-old plants were used in the experiments.

Experiment 1. Expression of Marker Genes of the ORA59- and MYC2-Branch During RhizobacteriaMediated ISR We evaluated gene expression of JA/ETregulated genes $O R A 59$ and $P D F 1.2$ and of the JA-regulated genes MYC 2 and VSP 2 in A. thaliana Col-0 and mutants myc2 and ora59. The four treatments, consisting of control plants (C), rhizobacteria-treated plants (R), control plants infested with $M$. brassicae (CM), rhizobacteria-treated plants infested with $M$. brassicae (RM) were arranged for each line. In herbivory treatments, two larvae per plant were placed on the leaves. For each treatment, four to five biological replicates were used, each consisting of pooled leaves taken from four to five plates (each containing 11 to 12 seedlings) to ensure sufficient plant material for gene transcript analysis. Leaves were harvested at $24 \mathrm{~h}$ after insect infestation (hpi). Leaves of uninfested plants were treated and harvested similarly as those of infested plants. Leaf samples were frozen immediately in liquid nitrogen and stored at $-80^{\circ} \mathrm{C}$ for further RNA extraction. Using the same batch of plants, performance of the caterpillars feeding on Arabidopsis wild type Col-0, and on the myc 2 and ora 59 mutants, and plant biomass were assessed as described below.

Leaf samples were ground in liquid nitrogen, and total RNA was extracted and purified following the protocol of RNeasy plant mini kit (Qiagen, Hilden, Germany). Measurement of RNA quality and procedure of cDNA synthesis followed methods described in Pangesti et al. (2015). Sequences of the primers used in this study for the genes MYC2/JASMONATE INSENSITIVE1 (MYC2), VEGETATIVE STORAGE PROTEIN 2 (VSP2), OCTADECANOID-RESPONSIVE ARABIDOPSIS 59 (ORA59), PLANT DEFENSIN 1.2 (PDF1.2) are provided in the Supplementary materials. Efficiency of each primer was determined before qRT-PCR analysis (CFX96 ${ }^{\mathrm{TM}}$ Real-Time System, BIO-RAD, Hercules, CA, USA). Thermal cycling conditions consisted of $95^{\circ} \mathrm{C}$ for $3 \mathrm{~min}$, followed by 40 cycles of $95^{\circ} \mathrm{C}$ for $15 \mathrm{~s}$ and $62^{\circ} \mathrm{C}$ for $45 \mathrm{~s}$. For each primer pair, controls without addition of template were included to confirm that primer dimers were not interfering with detection of amplification. The transcript level for each tested gene was calculated relative to the reference genes ELONGATION FACTOR $1 \alpha(E F 1 \alpha)$ and $F$ BOX FAMILY PROTEIN (FBOX) using the $2^{\Delta \Delta \mathrm{Ct}}$ method (Livak and Schmittgen 2001).

Performance of $M$. brassicae and Measurement of Plant Biomass From the same batch of plants as for gene transcript analysis, additional plates were arranged to evaluate herbivore performance and plant biomass. Larvae that were feeding on 
Arabidopsis wild type Col-0, myc2, or ora59 were weighed at $4 \mathrm{~d}$ post infestation (dpi), to the nearest $0.001 \mathrm{mg}$ on a microbalance (CP2P, Sartorius AG, Germany). Afterwards, a pool of plant leaf material left in each replicate (squared plates) from control plants infested with M. brassicae (CM), rhizobacteria-treated plants infested with $M$. brassicae, as well as control plants (C) and rhizobacteria-treated plants (R) were weighed to the nearest $0.1 \mathrm{mg}$ (Mettler Toledo, Switzerland). Bioassays were performed in a growth chamber under similar conditions as described for plant cultivation.

Experiment 2. Changes in Glucosinolate and Camalexin Levels During Rhizobacteria-ISR in the JA and ETDefective Mutants dde2-2 and ein2-1 We evaluated the concentrations of glucosinolates (GLS) and camalexin in A. thaliana Col-0, in the JA-biosynthesis defective mutant dde2-2 and in the ET-signaling defective mutant ein2-1. Using the same batch of plants, performance of the caterpillars feeding on Arabidopsis wild type Col-0, dde2-2, ein2-1, and plant biomass were measured as described above.

Glucosinolate and Camalexin Analysis For glucosinolate (GLS) and camalexin analysis, four to five biological replicates were used, each consisting of pooled leaves taken from four to five plates (each containing 11 to 12 seedlings) to ensure sufficient material was collected for chemical analysis. Leaves were harvested at 4 dpi. Leaves of uninfested plants were treated and harvested at similar time points as those of infested plants. Leaf samples were frozen immediately in liquid nitrogen and stored at $-80^{\circ} \mathrm{C}$ for further analysis. Leaf samples were ground to a fine powder in liquid nitrogen and then lyophilized for $48 \mathrm{~h}$ at $-80^{\circ} \mathrm{C}$ and pressure of $<10 \mathrm{mB}$.

Approximately $20 \mathrm{mg}$ of lyophilized tissue were weighed for glucosinolate (GLS) analysis, and the exact weight of the tissue was recorded and used to calculate the GLS concentration. The GLS were extracted with $1 \mathrm{ml}$ of $80 \%$ methanol solution containing $0.05 \mathrm{mM}$ intact 4hydroxybenzylglucosinolate as internal standard, and analyzed by HPLC-UV as described in Burow et al. (2006). Camalexin was analyzed in the flow-through samples resulting from the extraction procedure for GLS analysis. In GLS extraction, the raw extract was loaded onto DEAE Sephadex, the resulting flow-through when loading the extract was collected in a 96 deep-well plate and directly analyzed by LC-MS/MS.

Experiment 3. Changes in Glucosinolates and Camalexin During Rhizobacteria-Mediated ISR in the Transcription Factor Defective Mutants myc2 and ora59 We evaluated concentrations of GLS and camalexin in A. thaliana Col-0, in the ORA59-branch mutant ora59 and in the JA-regulated MYC2-branch mutant myc2 plants as described for experiment 2. Using the same batch of plants, performance of the caterpillar feeding on Arabidopsis wild type Col-0, ora59, $m y c 2$, and plant biomass of all lines were measured as described above. Analysis of GLS and camalexin content in plant shoots was performed as described for experiment 2 .

Statistical Analysis Gene expression data were transformed $[\log (\mathrm{x}+1)]$ and analyzed with one-way ANOVA to compare treatments within each line, whereas two-way ANOVA was used to compare treatments between lines. Glucosinolate data were analyzed with multivariate Projection to Latent Structures-Discriminant Analysis (PLS-DA) (SIMCA P + 12.0, Umetrics AB, Umeå, Sweden). Analysis of individual and total aliphatic and indolic GLS were analyzed with oneway ANOVA to compare treatments within each line, whereas two-way ANOVA was used to compare treatments between lines. Camalexin data were log-transformed and analyzed with one-way ANOVA to compare treatments within each line, whereas two-way ANOVA was used to compare treatments between lines. Mamestra brassicae performance data were analyzed with Linear Mixed Models (LMMs) within each line, with treatment as fixed factor and plate as random factor. Effect of rhizobacterial colonization on $M$. brassicae performance also was assessed between lines. Data of plant shoot and root biomass were analyzed with one-way ANOVA to compare treatments within each line, whereas two-way ANOVA was used to compare treatments between lines. Results of two-way analysis are reported in Table 1.

\section{Results}

Rhizobacterial Colonization of Arabidopsis thaliana Modifies Plant Signaling by Prioritizing Expression of Genes in the ORA59-Branch Over Those in the MYC2Branch To test the hypothesis that rhizobacterial colonization triggered enhanced expression of JA- and ET-regulated genes in Col-0, we evaluated gene expression of the JA-regulated genes MYC2 and VSP2 and the JA/ET-regulated genes ORA59 and $P D F 1.2$ at $24 \mathrm{~h}$ after $M$. brassicae infestation. The following treatments were compared: control plants infested with M. brassicae (CM), rhizobacteria-treated plants infested with M. brassicae (RM), as well as uninfested control plants (C) and rhizobacteria-treated plants (R) in wild type $A$. thaliana Col-0, and the mutants myc 2 and ora 59. In Col-0 plants, feeding damage by $M$. brassicae on control plants (CM) and rhizobacteria-treated plants (RM) resulted in a slight upregulation of $M Y C 2$ in comparison to control plants $(\mathrm{C})$, but rhizobacterial colonization did not affect this induction (Fig. 1a). In the mutants myc 2 and ora59, the expression of $M Y C 2$ was lower in comparison to its expression in Col-0, and it was not induced by herbivory. The mutants myc 2 and ora59 are null mutants, the fact that expression of MYC2 and ORA59 genes was found in each of the mutants suggests that there are 
Table 1 Effect of the factors treatment, line and their interaction term on levels of transcripts and defensive chemicals, as well as on herbivore performance

\begin{tabular}{|c|c|c|c|c|c|c|c|c|c|}
\hline & \multicolumn{3}{|c|}{ Treatment } & \multicolumn{3}{|l|}{ Line } & \multicolumn{3}{|c|}{ Treatment $x$ Line } \\
\hline & $d f$ & $F$ & $P$ & $d f$ & $F$ & $P$ & $d f$ & $F$ & $P$ \\
\hline \multicolumn{10}{|c|}{ Gene transcription: Col- 0, myc 2 , ora $59^{\text {a }}$} \\
\hline$M Y C 2$ & 3,50 & 5.75 & 0.002 & 2,50 & 28.50 & $<0.001$ & 6,50 & 3.09 & 0.014 \\
\hline$V S P 2$ & 3,50 & 100.62 & $<0.001$ & 2,50 & 1.85 & 0.170 & 6,50 & 0.67 & 0.677 \\
\hline ORA59 & 3,50 & 23.31 & $<0.001$ & 2,50 & 27.25 & $<0.001$ & 6,50 & 3.37 & 0.009 \\
\hline PDF1.2 & 3,50 & 115.18 & $<0.001$ & 2,50 & 65.32 & $<0.001$ & 6,50 & 65.32 & $<0.001$ \\
\hline \multicolumn{10}{|c|}{ Chemistry $^{\mathrm{a}}$ and herbivore performance ${ }^{\mathrm{b}}:$ Col- 0 , dde2-2, ein $2-1$} \\
\hline Aliphatic GLS & 3,59 & 18.59 & $<0.001$ & 2,59 & 98.94 & $<0.001$ & 6,59 & 8.83 & $<0.001$ \\
\hline Indole GLS & 3,59 & 166.68 & $<0.001$ & 2,59 & 224.12 & $<0.001$ & 6,59 & 45.18 & $<0.001$ \\
\hline Camalexin & 3,59 & 58.19 & $<0.001$ & 2,59 & 17.65 & $<0.001$ & 6,59 & 3.34 & 0.008 \\
\hline Herbivore & 1,104 & 7.06 & 0.009 & 2,104 & 20.16 & $<0.001$ & 2,104 & 0.74 & 0.692 \\
\hline \multicolumn{10}{|c|}{ Chemistry $^{\mathrm{a}}$ and herbivore performance ${ }^{\mathrm{b}}:$ Col- 0, myc 2 , ora 59} \\
\hline Aliphatic GLS & 3,59 & 18.99 & $<0.001$ & 2,59 & 5.63 & 0.001 & 6,59 & 0.32 & 0.92 \\
\hline Indole GLS & 3,59 & 60.13 & $<0.001$ & 2,59 & 6.58 & 0.003 & 6,59 & 2.81 & 0.02 \\
\hline Camalexin & 3,59 & 37.88 & $<0.001$ & 2,59 & 12.89 & $<0.001$ & 6,59 & 0.80 & 0.575 \\
\hline Herbivore & 1,484 & 45.93 & $<0.001$ & 1,484 & 7.12 & 0.029 & 1,484 & 0.22 & 0.897 \\
\hline
\end{tabular}

${ }^{\mathrm{a}}$ Two-way ANOVA; ${ }^{\mathrm{b}}$ Linear Mixed Model, $F$-value represents Wald statistic

proteins, which have similar functions, thus the expression of the down-stream genes is not $100 \%$ reduced. Similar to the expression of $M Y C 2$, in Col-0, feeding damage by $M$. brassicae on control plants $(\mathrm{CM})$ and rhizobacteriatreated plants (RM) resulted in up-regulation of VSP2 in comparison to control plants $(\mathrm{C})$, and this up-regulation was not affected by rhizobacterial colonization (Fig. 1b). In the mutants myc 2 and ora59, the expression of VSP2 was comparable to its expression in Col-0, and also was induced by herbivory. Overall, the JA-regulated genes $M Y C 2$ and VSP2 are induced by herbivory, but are not affected by rhizobacterial colonization.

In A. thaliana Col-0 plants, both rhizobacterial colonization with or without the herbivore (R and RM), and herbivory by M. brassicae (CM) resulted in up-regulation of ORA59 (Fig. 1c). The expression of ORA59 in R plants was higher than in CM and similar to RM. In the mutants $m y c 2$ and ora59, the expression of the gene ORA59 was lower in comparison to its expression in Col-0, and only slightly induced by rhizobacterial colonization (R and RM treatments) although not by herbivory (CM treatment). Similar to the expression pattern of ORA59, at $24 \mathrm{hpi}$ in Col-0 plants, rhizobacterial colonization with or without herbivory ( $\mathrm{R}$ and $\mathrm{RM}$ ), and $M$. brassicae feeding (CM) resulted in up-regulation of PDF1.2 (Fig. 1d), although the induction by rhizobacterial colonization was stronger than by herbivory. In the mutant $m y c 2$, the induction of PDF1.2 was stronger than in Col-0, and also was induced by herbivory and rhizobacterial colonization. In contrast, in the mutant ora59, the induction of PDF1.2 was lower than in Col-0 plants, and was only slightly induced by rhizobacterial colonization but not by herbivory. Taken together, rhizobacterial colonization resulted in higher levels of expression of the JA/ET-regulated genes PDF1.2 and ORA59 than herbivore feeding alone (Fig. 1c-e).

Rhizobacterial Colonization Enhances the Synthesis of Aliphatic GLS and Suppresses the Herbivore-Induced Levels of Indolic GLS The analysis of GLS in A. thaliana Col-0 was repeated twice (Exp. 2 and 3) with similar results (Tables S1-S3). The Projection to Latent StructuresDiscriminant Analysis (PLS-DA) of data sets from both experiments showed a similar pattern, and here only the PLSDA plot from experiment 2 is shown (Fig. 2). A PLS-DA analysis of GLS in the four treatments showed two significant principal components (PC) explaining 52.6 and $35.1 \%$ of the total variance, respectively. The first PC separated the GLS based on the presence/absence of caterpillars, whereas the second PC separated the GLS based on the presence/absence of rhizobacteria. In the shoot, a total of six aliphatic and four indolic GLS were detected. Three aliphatic GLS and two indolic GLS had a VIP value higher than 1 (Table S3, Exp. 2 and 3). VIP values indicate the variable importance in the projection, and those larger than 1 are the most influential for the model (Eriksson et al. 2006). In decreasing order of importance, these compounds were $8 \mathrm{MSOO}$ (glucohirsutin), $7 \mathrm{MSOH}$ (glucoibarin), 1MOI3M (neoglucobrassicin), I3M (glucobrassicin), and 4MTB (glucoerucin) (Table S3). In 
a

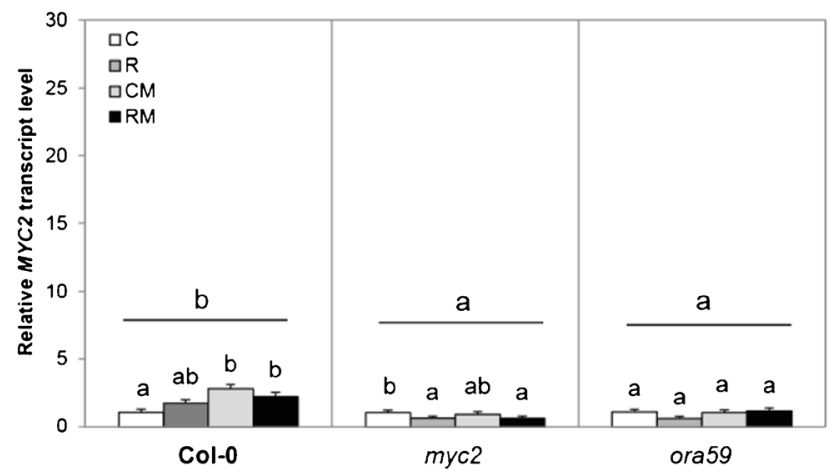

C

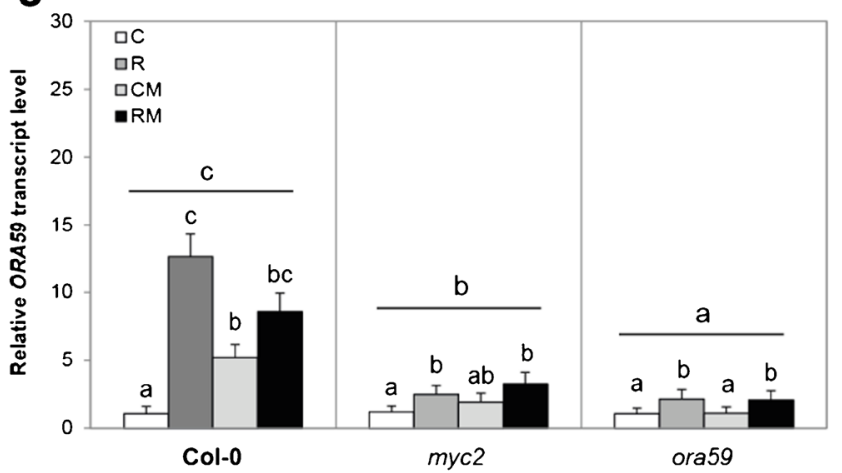

b

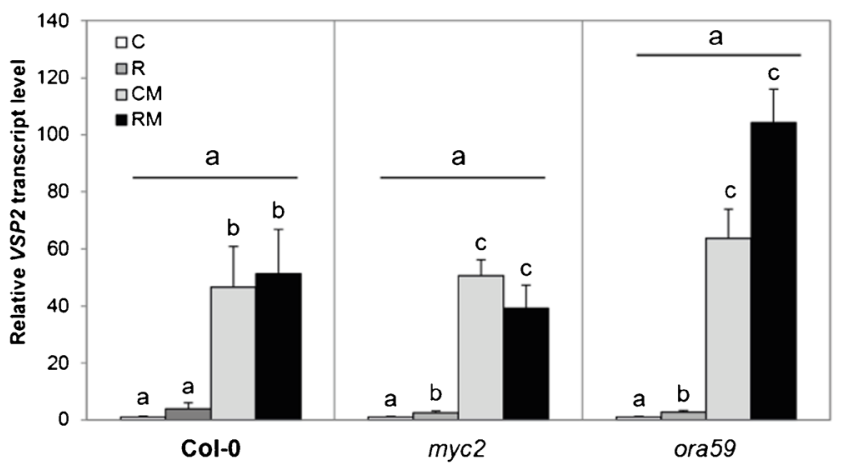

d

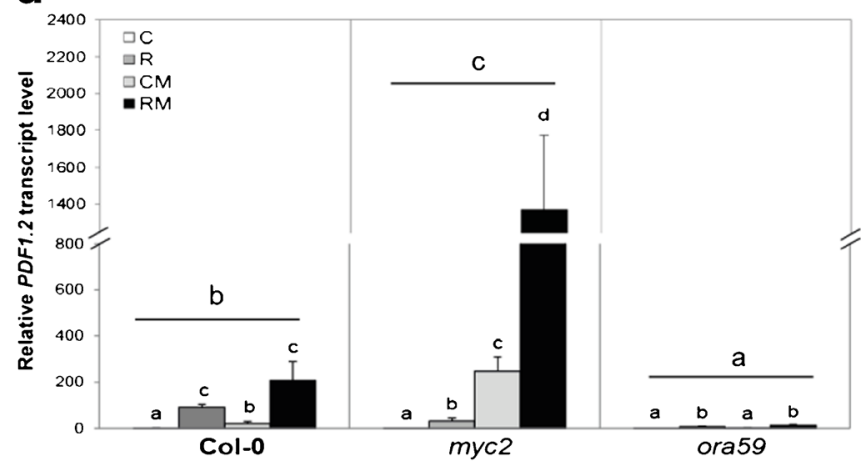

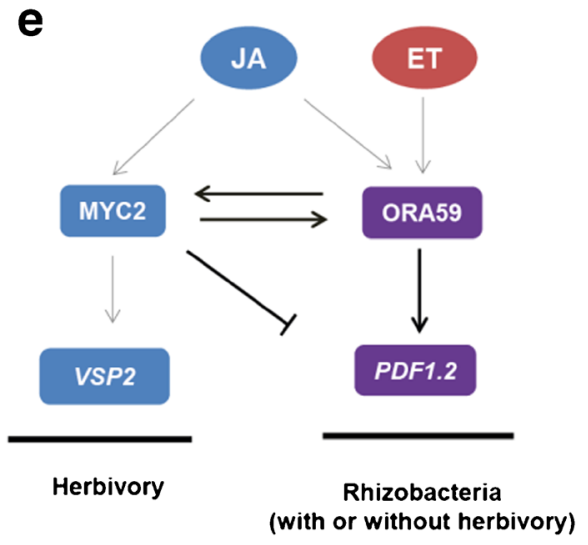

Fig 1 Relative transcript levels of $M Y C 2$ a, VSP2 b, ORA59 c, and $P D F 1.2$ d. Expression of $M Y C 2$ and $V S P 2$ genes are activated by the jasmonic acid (JA) pathway. Expression of ORA59 and PDF1.2 are activated by JA and ethylene (ET) pathways. Treatments are control plants (C), rhizobacteria-treated plants $(\mathbf{R})$, control plants infested with two neonate larvae of Mamestra brassicae (CM), or rhizobacteria-treated plants infested with M. brassicae (RM) for 24 hpi. Transcript levels $($ mean $\pm \mathrm{SE})$ of tested genes were normalized relative to reference genes $E F 1 \alpha$ and $F B O X$, and measured relative to the control plants $(N=3-5$

replicates, each from a pool of shoots collected from 3 to 5 plates). Different letters over the bars indicate significant differences within a line (one-way ANOVA, LSD post hoc test, $P<0.05$ ), and letters over horizontal line indicate differences between lines (two-way ANOVA, LSD post hoc test, $P<0.05$ ). (E) Working model of rhizobacterial induction of JA- and ET-regulated genes upon caterpillar feeding. Black arrows represent induction, truncated line represents suppression. Grey lines represent findings from previous studies (Schweizer et al. 2013; Verhage et al. 2011)

A. thaliana Col-0, the aliphatic GLS 3MSOP, 7MSOH, and $8 \mathrm{MSOO}$ were induced by rhizobacterial colonization, with the highest levels in RM plants (Tables S1, S2). In contrast, the aliphatic GLS 4MSOB and 5MSOP were induced by herbivory, whereas the aliphatic GLS 4MTB occurred at significantly lower levels in plants exposed to herbivory than in uninfested plants. Interestingly, the indolic GLS 1MOI3M and I3M were induced only by herbivory, with higher levels in CM than in RM. In the mutants dde2-2, ein2-1, myc2, and ora59, GLS profiles were separated based on the presence or absence of caterpillars or rhizobacteria in a similar way to Col-0 (Fig. S1).

We evaluated the effect of treatment on GLS levels in wild type A. thaliana Col-0, and in the mutants dde2-2, ein2-1, 


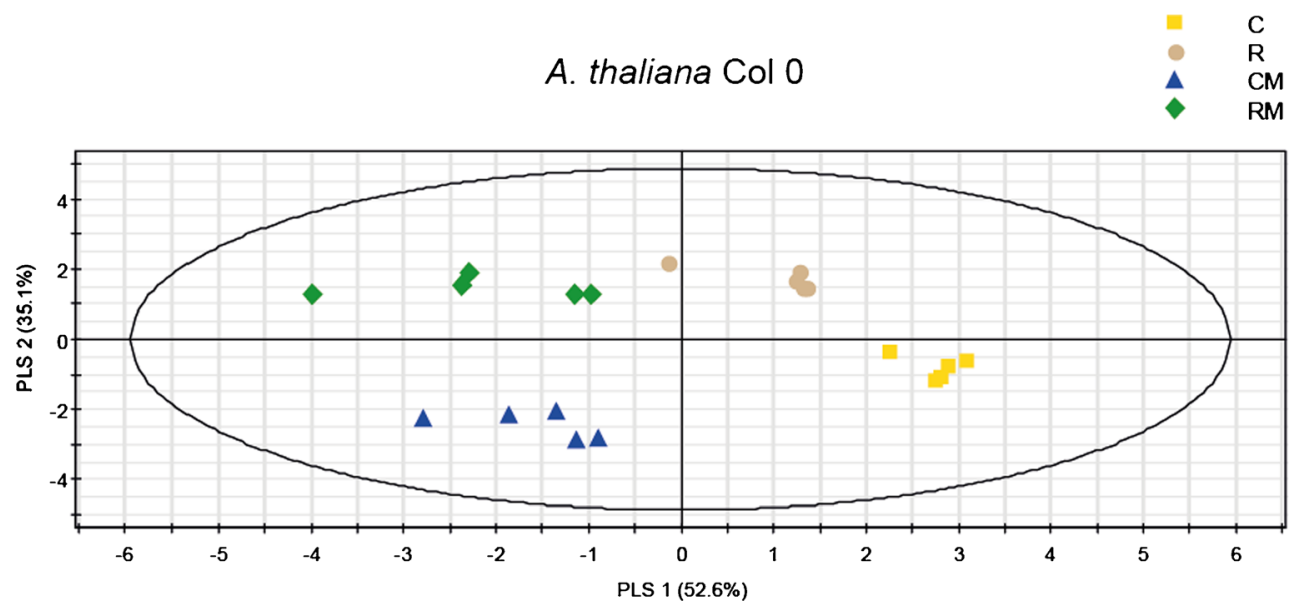

Fig 2 Projection to Latent Structures Discriminant Analysis (PLS-DA) comparison of Arabidopsis thaliana Col-0 GLS profiles in shoots of control plants $(\mathbf{C})$, rhizobacteria-treated plants $(\mathbf{R})$, control plants infested with Mamestra brassicae (CM), or rhizobacteria-treated plants infested with M. brassicae (RM). Grouping pattern of samples according to the

$m y c 2$, and $o r a 59$ to test the hypothesis that functional JA- and ET-signaling pathways are required for rhizobacterial modification of the synthesis of GLS. The total levels of aliphatic glucosinolates were reduced in all four mutants compared to the levels in Col-0 (Figs. 3a, c). A first experiment showed that rhizobacterial colonization (R), M. brassicae feeding (CM), and the combination of both treatments (RM) induced the biosynthesis of aliphatic GLS in Col-0, with higher levels in RM than in CM (Fig. 3a, Table S1). In contrast to what was observed for Col-0, in mutants dde2-2 and ein 2-1 herbivory alone did not induce the levels of aliphatic GLS (Fig. 3a). A subsequent experiment with A. thaliana Col-0, myc2, and ora59 plants, showed that only rhizobacterial colonization (treatments R and RM) induced the synthesis of aliphatic GLS in Col-0, and such induction was conserved in the myc2 and ora59 mutants (Fig. 3c). Taken together, these results show that the biosynthesis of aliphatic GLS requires functional JAand ET- signaling pathways, and that rhizobacterial colonization induced the levels of aliphatic GLS (Fig. 3e).

In contrast, levels of total indolic GLS were reduced in the JA mutants dde2-2 and $m y c 2$, but did not change in ora59, and even increased in ein2-1 compared to Col-0 plants (Figs. 3b, d). In the two experiments with A. thaliana Col-0, feeding by $M$. brassicae (CM) induced the synthesis of indolic GLS, but in contrast to the levels of aliphatic glucosinolates, rhizobacterial colonization suppressed the synthesis of the indolic GLS upon caterpillar feeding (RM) (Figs. 3b, d). Interestingly, the suppressive effect of rhizobacteria on herbivore-induced levels of indolic GLS in Col-0, as seen in the comparison between CM and RM, was not observed in the $m y c 2$ mutant, whereas the herbivore-induction of indole GLS was not observed in the dde2-2 plants. Overall, M. brassicae feeding on control plants (CM) induced synthesis of indolic GLS to a higher level compared to feeding on rhizobacteria- first two principal components and the Hotelling's ellipse of the $95 \%$ confidence interval for the observations. Each point represents a replicate $(N=5)$, each replicate consisted of a pooled sample of $A$. thaliana shoots collected from 5 plates

colonized plants (RM), and this effect on indolic GLS was mediated by JA signaling (Fig. 3e).

Rhizobacterial Colonization and Herbivory Induce Biosynthesis of Camalexin We evaluated camalexin levels, comparing the four treatments in wild type A. thaliana Col-0, and in the mutants dde2-2, ein 2-1, myc2, and ora59 to test the hypothesis that functional JA- and ET-signaling pathways are required for rhizobacterial modification of the biosynthesis of this plant defensive compound. The biosynthesis of camalexin was reduced in the dde2-2, myc2, and ora59 mutants compared to Col-0 but not in the ein2-1 mutants. In Col-0, rhizobacterial colonization (R), M. brassicae feeding (CM), and the combination of both treatments (RM) induced camalexin, and this pattern was conserved in the dde2-2, ein 2-1, myc2, and ora59 mutants (Fig. 4a-c).

Rhizobacteria-Mediated Induced Systemic Resistance Against the Generalist Caterpillar M. brassicae Requires Functional JA- and ET-Signaling Pathways but is Independent of the Transcription Factors MYC2 and ORA59 We evaluated the performance of $M$. brassicae caterpillars feeding on control (CM) and rhizobacteria-treated (RM) plants for Col-0 wild type and the mutants dde2-2, $m y c 2$, ein 2-1, and ora59, to test the hypothesis that rhizobacteria-induced plant resistance to $M$. brassicae requires intact JA- and ET-signaling pathways. In Col-0 plants, rhizobacterial colonization resulted in reduced larval weight of $M$. brassicae $(d f=1,31.5$; Wald stat. $=4.94 ; P=0.034)$. In contrast, when feeding on dde2-2 and ein2-1 plants, rhizobacterial colonization did not affect larval weight (Fig. 5a). In a different experiment, rhizobacterial colonization of $A$. thaliana Col-0 consistently resulted in reduced larval weight of $M$. brassicae, both in Col-0 ( $d f=1,77.4$; Wald stat. 

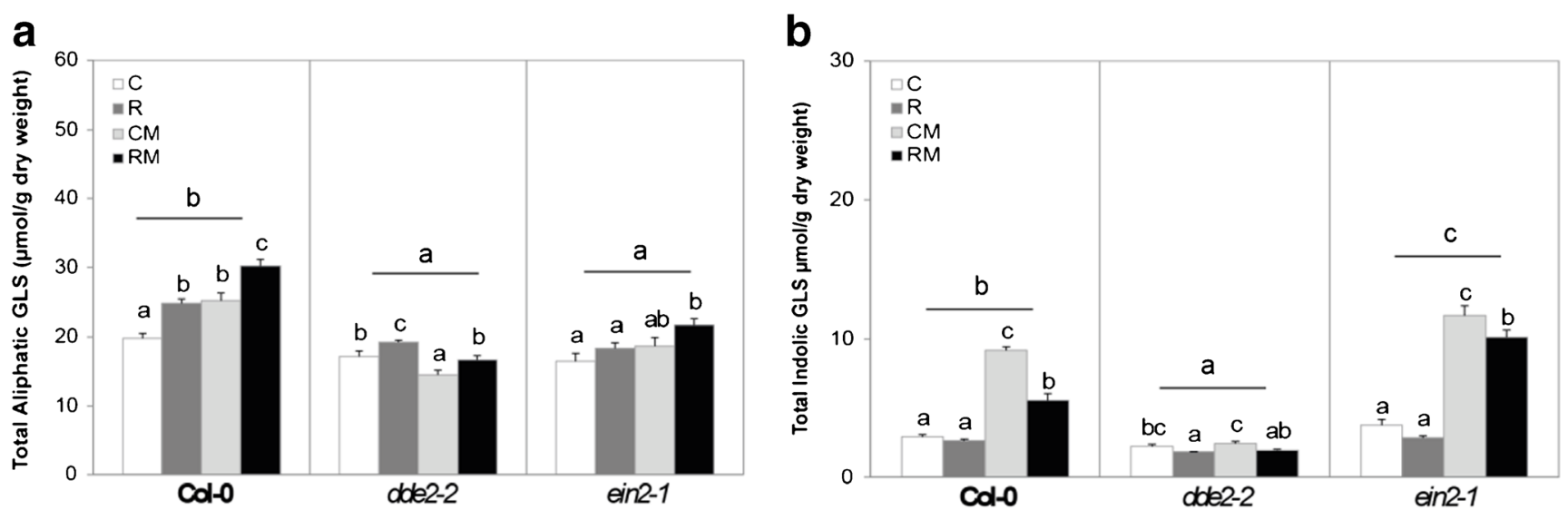

C

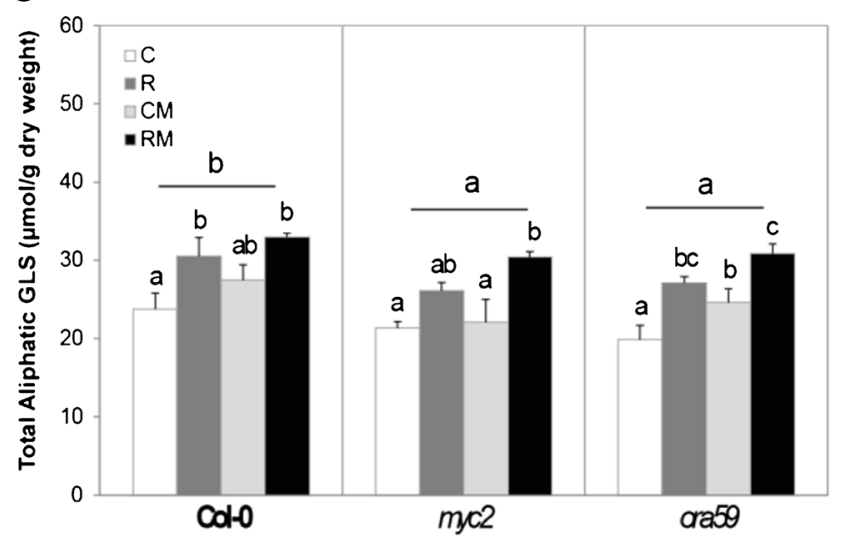

d
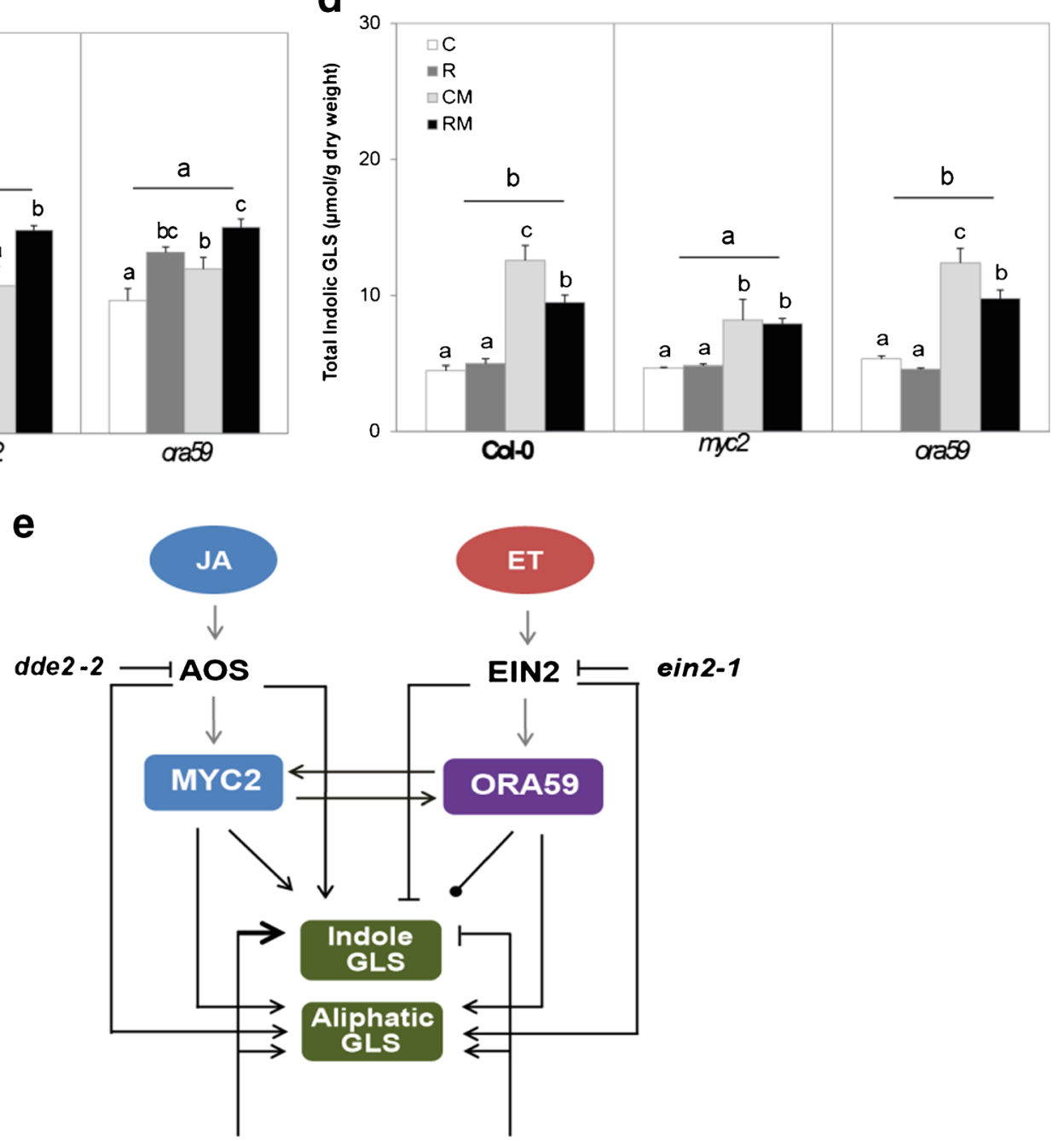

ein2-1

Herbivory Rhizobacteria

(with or without herbivory)

$=11.81 ; P<0.001)$, and when feeding on myc2 and ora59 (Fig. 5b) (myc2: $d f=1,84.5$; Wald stat. $=6.98 ; P=0.01$; ora59: $d f=1,85.4$; Wald stat. $=7.77 ; P=0.007$ ). Data presented in Fig. 5b are the combined results on M. brassicae performance from two independent experiments. In all experiments, the density of rhizobacteria colonizing the roots was above the required threshold for ISR induction (Table S4). Taken together, the rhizobacteria- 
Fig 3 Total levels of aliphatic (a, c) and indole glucosinolates $(\mathbf{b}, \mathbf{d})$ in shoots of Arabidopsis thaliana Col-0, and the mutants dde2-2, ein2-1, $m y c 2$, and ora59. Treatments are control plants (C), rhizobacteria-treated plants $(\mathbf{R})$, control plants infested with two neonate larvae of Mamestra brassicae $(\mathbf{C M})$, or rhizobacteria-treated plants infested with M. brassicae (RM) for $4 \mathrm{~d}(N=5$ replicates, each consisting of a pool of shoots collected from 5 plates). Different letters above the bars indicate significant differences within a line (one-way ANOVA, LSD post hoc test, $P<0.05$ ), and letters above horizontal lines indicate differences between lines (two-way ANOVA, LSD post hoc test, $P<0.05$ ). Panels A and $\mathrm{B}$, on the one hand, and $\mathrm{C}$ and $\mathrm{D}$, on the other, represent two different experiments. (E) Working model of rhizobacteria-triggered modification of GLS profile upon caterpillar feeding (RM) represented in black lines compared to control plant infested with caterpillar (CM) in A. thaliana represented in grey lines. Arrows represent induction, truncated lines represent suppression; line ending in a dot indicates no effect. Grey arrows represent information from literature

mediated ISR resulted in reduced $M$. brassicae larval weight compared to control treatments, and whereas functional JA- and ET-signaling were required, the rhizobacteria-mediated ISR was independent of the transcription factors MYC2 and ORA59.

Rhizobacterial colonization had a strong effect on the shoot and root fresh weight in comparison to control plants. Under caterpillar attack, rhizobacteria-treated plants (RM) had stronger shoot and root growth in comparison to control plants infested with caterpillars (CM). In the mutants dde2-2, ein21, myc2, and ora59, shoot and root biomass of plants in the four treatment groups showed a pattern similar to that of wild type plants (Fig. S2).

\section{Discussion}

The present study shows a consistent effect of the rhizobacterium $P$. simiae WCS417r in triggering ISR that negatively affects the performance of the generalist caterpillar M. brassicae. The results show that while herbivory by this a

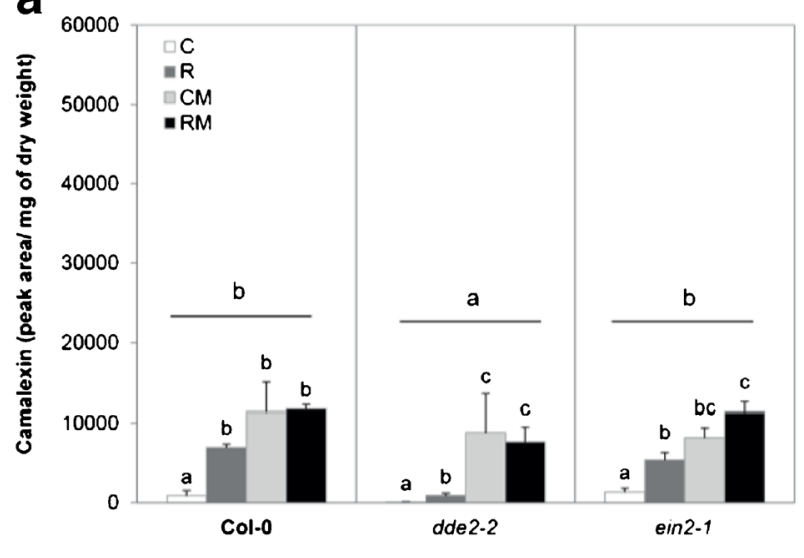

b

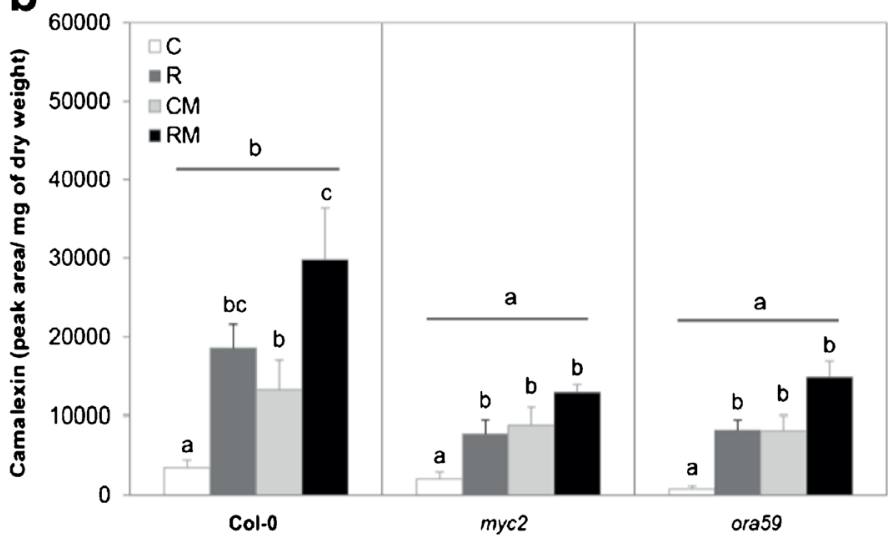

C

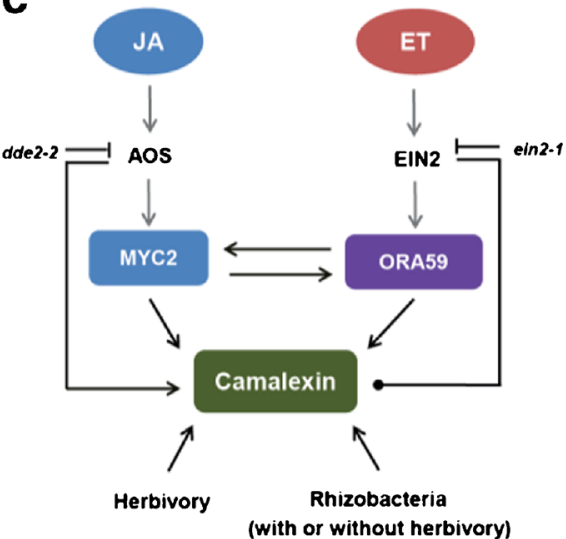

Fig 4 Relative concentration of camalexin (expressed in peak area units) in shoots of a Arabidopsis thaliana Col-0 and the mutants dde2-2 and ein 2-1. b A. thaliana Col-0 and the mutants myc2 and ora59. Treatments are: control plants c, rhizobacteria-treated plants $(\mathbf{R})$, control plants infested with Mamestra brassicae $(\mathbf{C M})$, or rhizobacteria-treated plants infested with two neonate larvae of $M$. brassicae (RM) for $4 \mathrm{~d}(N=5$ replicates, each composed of pooled shoots collected from 5 plates).
Panels A and B represent two different experiments. Different letters over the bars indicate significant differences within a line (one-way ANOVA, LSD post hoc test, $P<0.05)$, and letters over horizontal line indicate differences between lines (two-way ANOVA. LSD post hoc test, $P<0.05)$. Arrows represent induction, line ending in a dot indicates that no effect was found 


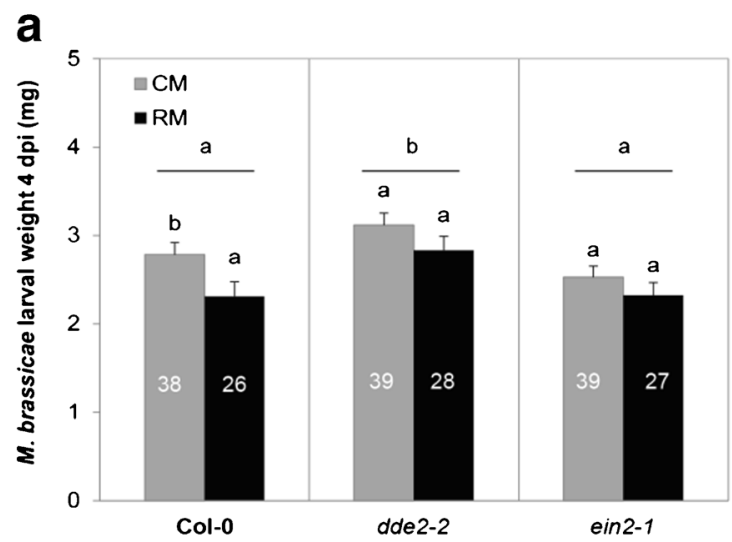

Fig 5 Performance of Mamestra brassicae on control (CM) or rhizobacteria-treated plants (RM). Panels a $(N=14-23$ plates) and b ( $N=40-42$ plates) represent two different experiments, and data of panel $\mathrm{B}$ are from two independent experiments (see Fig. S1 for extra information). Larval weight was measured at $4 \mathrm{dpi}$, after infesting each plate with

generalist herbivore prioritizes activation of the MYC2branch of the JA-signaling pathway in the plant, rhizobacterial colonization causes a shift to a stronger activation of the ORA59-branch of the JA-signaling pathway (Fig. 1). However, the transcription factor ORA59 is not the only responsible transcription factor for the observed effect of rhizobacterial colonization on caterpillar growth, based on the observation that the effect of rhizobacterial colonization on $M$. brassicae larval weight remained the same on the ora59 mutant. Instead, we observed that functional JA- and ETsignaling pathways are required for rhizobacteria-ISR against M. brassicae. The rhizobacterium $P$. simiae WCS417r (formerly P. fluorescens WCS417r) used in this study is known to induce ISR against pathogens via the JA/ET signaling pathways too (Pieterse et al. 2002; 2014; Van der Ent et al. 2009). This suggests similarity in the mechanism by which plants mount an effective response upon rhizobacterial colonization against different types of attackers.

Rhizobacterial colonization alone or in combination with infestation by $M$. brassicae increased the expression of both the JA/ET-regulated transcription factor ORA59 and the marker gene $P D F 1.2$. Using the same rhizobacterium-plant combination, previous studies found that rhizobacterial colonization of plant roots enhanced expression of PDF 1.2 only after herbivory (Pangesti et al. 2015; Pineda et al. 2012; Van Oosten et al. 2008), a phenomenon known as "priming" of induced plant defense (Conrath 2009). Interestingly, our results show that rhizobacterial colonization alone (R) induced expression of PDF1.2 to the same levels as in the combined treatment of rhizobacterial colonization and $M$. brassicae infestation (RM). The gene PDF1.2 encodes a plant defensin that is a basic peptide having antimicrobial activity against pathogens (Sels et al. 2008; Thomma et al. 2002). Here, we show that colonization by the beneficial rhizobacterium P. simiae WCS417r also induces the expression of PDF1.2,

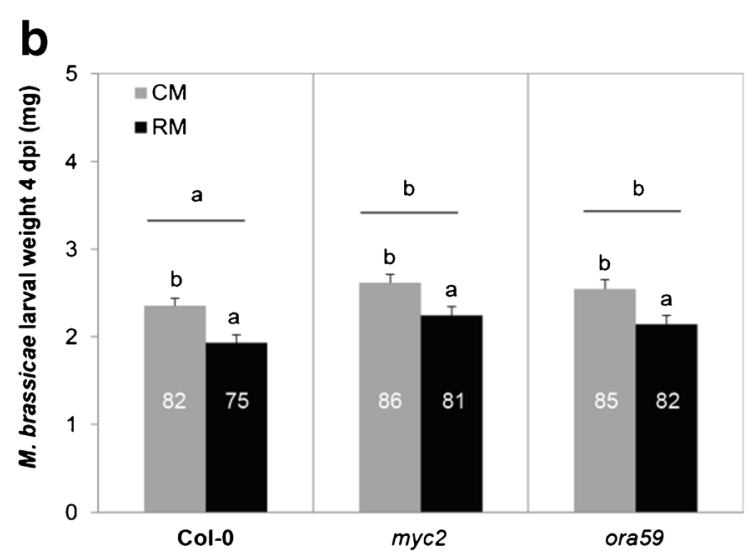

two neonate larvae. Numbers in each bar represent number of larvae surviving on the day of weight measurement. Data shown are means $( \pm$ SE) of larval weight. Different letters over the bars indicate significant differences within line, and letters over horizontal line indicate differences between lines (LMM, $P<0.05$, LSD test)

which suggests that the plant initially recognizes this rhizobacterium as a pathogenic organism, and therefore, expresses defense-associated genes that limit its colonization. The results support a new interesting aspect of beneficial microbe-plant interactions, as it has been proposed that plants initially recognize the root-associated microbes as attacker, and therefore, produce compounds that can limit the development of microbes (Pozo and Azcon-Aguilar 2007; Zamioudis and Pieterse 2012). Another hypothesis is that beneficial microbes induce plant defensive compounds that could limit its competitors for plant resources. The role of defensin peptides in the inhibition of bacterial and fungal growth has been extensively reported, whereas in plant defense to herbivorous insects, few studies have addressed their role. An expression of $\mathrm{BrD} 1$ protein, a plant defensin from Brassica rapa, in transgenic rice has suggested that the protein has insecticidal activity to nymphs of the brown planthopper Nilaparvata lugens (Choi et al. 2009). In a study on A. thaliana, it was found that $P$. rapae oral secretion induces the expression of $P D F 1.2$ (Verhage et al. 2011). Interestingly, there is a strong interest in the importance of microbes in insect oral secretions or gut for the immune system and growth of herbivores as reviewed in Engel and Moran (2013), that can also influence plantinsect interactions. Further studies are required to investigate if the up-regulation of defensin peptides in plants colonized by rhizobacteria could negatively affect insect-associated microbes and suppress the insect's immune system, thus making the plant more resistant to the insect herbivore.

Our data show that rhizobacterial colonization consistently enhanced the levels of aliphatic GLS, suppressed the herbivore-induced levels of indolic GLS, and thereby significantly affected GLS composition. Moreover, rhizobacterial colonization or caterpillar feeding also consistently induced synthesis of camalexin in the shoot. Using the same method of in vitro assays, colonization of $A$. thaliana Col-0 roots by 
the $P$. fluorescens strain SS101 induced accumulation of both aliphatic and indolic GLS in the shoots and in the roots, in the absence of herbivory (Van de Mortel et al. 2012), as well as upregulation of camalexin synthesis in local and systemic tissues. Our present study and the study by Van de Mortel et al. (2012) indicate that different strains of a rhizobacterial species colonizing Arabidopsis roots can influence the chemical composition in systemic tissues that may contribute to ISR to herbivorous insects. Previous studies mostly have indicated that camalexin is regulated via the SA pathway (Glawischnig 2007; Glazebrook 2005). The results of the present study show that the JA pathway and transcription factors MYC2 and ORA59 also are involved in the regulation of camalexin synthesis. Our results, thus, reveal new aspects of the biological role of camalexin and the role of signaling pathways underlying the synthesis of this compound. The experiments with mutants, as presented here, show that activation of the JA signaling pathway induces the synthesis of aliphatic and indolic GLS, whereas the ET pathway represses the synthesis of indolic GLS. By modulating both the JA- and ET pathways, $P$. simiae WCS417r colonization, changes GLS composition by enhancing the biosynthesis of aliphatic GLS and suppressing the biosynthesis of indolic GLS that is induced by herbivory. The sensitivity of $M$. brassicae to aliphatic GLS has been reported in a previous study (Beekwilder et al. 2008), showing that in the A. thaliana myb28myb29 double mutant lacking aliphatic GLS, the weight of $M$. brassicae increased 2.6 fold compared to the performance in wild type Col-0. Moreover, a negative correlation between the concentration of aliphatic GLS and performance of the generalist caterpillar $S$. exigua and the specialist $P$. rapae has been reported (Kos et al. 2012). Taken together, we propose that accumulation of aliphatic GLS synthesis can underly $P$. simiae WCS417r-mediated ISR against leaf-chewing M. brassicae caterpillars. A study using mutants lacking aliphatic GLS may unravel the underlying mechanisms of rhizobacteria-plant-insect interactions.

By using a closed in vitro system, we here showed that colonization by the rhizobacterium $P$. simiae WCS417r had a consistent negative effect on the performance of the generalist caterpillar M. brassicae, and that this is associated with prioritization of the JA/ET-regulated ORA59-branch over the JA-regulated MYC2-branch in the presence and absence of herbivory. By using an open system in soil, we previously found that the effect of rhizobacterium $P$. simiae WCS417r on plant direct defense against $M$. brassicae was variable, depending on soil composition (Pangesti et al. 2015). Moreover, it is known that in response to microbial attack and herbivore feeding, plants produce high levels of ET (De Vos et al. 2005), although microbial attack induces higher levels of ET in comparison to herbivore feeding. In this study, experiments were conducted in a closed system, and it is possible that in the early stage of rhizobacterial colonization, plants emit ET, and that accumulation of ET triggers prioritization of ORA59-branch even without caterpillar infestation. First, we propose that the prioritization of the ET signaling pathway, enhancing the synthesis of aliphatic GLS even without herbivore attack, may strengthen rhizobacteria-mediated ISR against the caterpillar $M$. brassicae. However, a mutation in the JA/ET-regulated ORA59, which is downstream of the knock-out genes in dde2-2 and ein2-1 mutants, does not have any effect on induction of rhizobacteria-mediated ISR against the caterpillars, suggesting that ORA59 alone does not explain rhizobacterial induced ISR against M. brassicae. It is possible that there is functional redundancy of ORA59 provided by other JA- and ET-regulated proteins, thus mutation of only ORA59 does not change the induction of rhizobacteria-mediated ISR against M. brassicae. A similar reasoning may apply for $M Y C 2$,

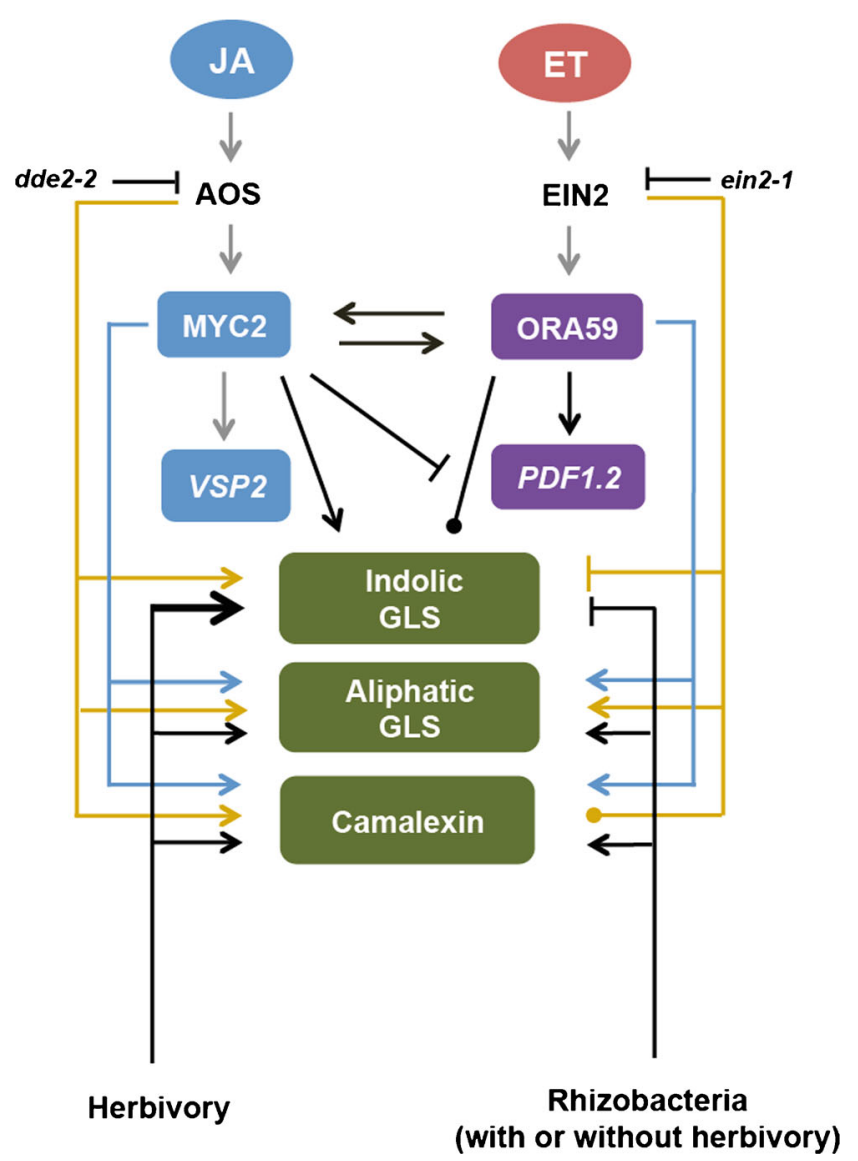

Fig 6 Working model of rhizobacteria-mediated induced systemic resistance (ISR) via jasmonic acid/ethylene (JA/ET)-dependent mechanisms based on studies in Arabidopsis thaliana Col-0. Rhizobacterial- and herbivory-induced modification of plant gene transcription, glucosinolates and camalexin biosynthesis are represented in black lines. Central component of JA- and ET-signaling pathways regulation of plant gene transcription and chemical biosynthesis are represented in orange and blue lines. Grey lines represent results from the literature (Schweizer et al. 2013.; Verhage et al. 2011). Arrows represent induction, truncated lines represent suppression; dotted line indicates no effect 
the function of which may be complemented by MYC3/4 (Schweizer et al. 2013). Since rhizobacteria-mediated ISR against caterpillars required both the JA- and ET signaling pathways (as observed with the mutants $d d e 2-2$ and ein21), whether other JA-/ET-targeted transcription factors mediate the regulation of rhizobacteria-plant-insect interactions remains to be investigated. Second, we propose that simpler nutrient composition in the half-strength Murashige \& Skoog (MS) media used in this study, compared to the nutrients available in soil, may result in more intense interactions between rhizobacteria and plants (Pangesti et al. 2015), and could be one of the factors that contributed to the consistent effect of rhizobacteria-mediated ISR against the generalist caterpillar M. brassicae. Moreover, in an open system, other microbes also can colonize plant roots and compete with the rhizobacterium, and may therefore modify the rhizobacterium-plant interactions (Shavit et al. 2013), which is not the case in the in vitro system used here.

In the present study, we found evidence that colonization of plant roots by rhizobacteria alters plant-insect interactions at the level of gene transcription, plant chemistry, and insect performance. Previous studies using the same rhizobacterium-plant combination recorded an up-regulation of the JA/ET-regulated genes such as PDF1.2, and HEL upon feeding by the caterpillars Spodoptera exigua (Van Oosten et al. 2008), M. brassicae (Pangesti et al. 2015), and the aphid Myzus persicae (Pineda et al. 2012). This study furthers our understanding of mechanisms of rhizobacteria-mediated ISR against leaf-chewing insects by showing not only that functional JA- and ET pathways are required, but also that ISR against $M$. brassicae is induced along the ORA59 branch and not the MYC2 branch of the octadecanoid signal-transduction pathway. Furthermore, this study also provides new information on the induction of defensive compounds, such as glucosinolates and camalexin by rhizobacterial colonization that can potentially explain the increased resistance to insect herbivores (Fig. 6). Recent experimental evidence is uncovering the beneficial contribution of microorganisms to the functioning of humans, insects, and plants by affecting growth, development, and immunity to diseases (Engel and Moran 2013; Selosse et al. 2014; Sugio et al. 2014). In rhizobacteriacolonized plants, we found a higher expression of the $P D F 1.2$ gene that encodes a plant defensin peptide, and higher levels of secondary metabolites such as camalexin, both known to have antimicrobial activity. This may be an initial response of plants to the recognition of the beneficial microbes. Whether these compounds have activity beyond antimicrobial effects, thus directly influencing insect physiology, or whether the compounds affect the insects indirectly by changing insect-associated microbes, thus modifying plantinsect interactions, could be fruitful questions for future research to unveil the mechanisms underlying beneficial microbe-plant-insect interactions.
Acknowledgments We thank Wim van Ieperen and Santiago Zabala Hidalgo for their help in measurement of light conditions in the climate cell. We thank Léon Westerd, André Gidding, and Frans van Aggelen for rearing the insects. We also thank Saskia C.M. van Wees for providing the mutant ora59. The research was financially supported by the Graduate School of Experimental Plant Sciences (EPS), Wageningen University.

Open Access This article is distributed under the terms of the Creative Commons Attribution 4.0 International License (http:// creativecommons.org/licenses/by/4.0/), which permits unrestricted use, distribution, and reproduction in any medium, provided you give appropriate credit to the original author(s) and the source, provide a link to the Creative Commons license, and indicate if changes were made.

\section{References}

Abe H, Urao T, Ito T, Seki M, Shinozaki K, Yamaguchi-Shinozaki K (2002) Arabidopsis AtMYC2 (bHLH) and AtMYB2 (MYB) function as transcriptional activators in abscisic acid signaling. Plant Cell 15:63-78

Beekwilder J, Van Leeuwen W, Van Dam NM, Bertossi M, Grandi V, Mizzi L, Soloviev M, Szabados L, Molthoff JW, Schipper B, Verbocht H, De Vos RCH, Morandini P, Aarts MGM, Bovy A (2008) The impact of the absence of aliphatic glucosinolates on insect herbivory in Arabidopsis. PLoS One 3, e2068

Berendsen RL, Van Verk MC, Stringlis IA, Zamioudis C, Tommassen J, Pieterse CMJ, Bakker PAHM (2015) Unearthing the genomes of plant-beneficial Pseudomonas model strains WCS368, WCS374 and WCS417. BMC Genomics 16:539

Bodenhausen N, Reymond P (2007) Signaling pathways controlling induced resistance to insect herbivores in Arabidopsis. Mol PlantMicrobe Interact 20:1406-1420

Burow M, Muller R, Gershenzon J, Wittstock U (2006) Altered glucosinolate hydrolysis in genetically engineered Arabidopsis thaliana and its influence on the larval development of Spodoptera littoralis. J Chem Ecol 32:2333-2349

Cartieaux F, Contesto C, Gallou A, Desbrosses G, Kopka J, Taconnat L, Renou JP, Touraine B (2008) Simultaneous interaction of Arabidopsis thaliana with Bradyrhizobium sp strain ORS278 and Pseudomonas syriugae pv. tomato DC3000 leads to complex transcriptome changes. Mol Plant-Microbe Interact 21:244-259

Choi MS, Kim YH, Park HM, Seo BY, Jung JK, Kim ST, Kim MC, Shin DB, Yun HT, Choi IS, Kim CK, Lee JY (2009) Expression of BrD1, a plant defensin from Brassica rapa, confers resistance against brown planthopper (Nilaparvata lugens) in transgenic rices. Mol Cell 28:131-137

Conrath U (2009) Priming of induced plant defense responses. Adv Bot Res 51:361-395

De Vos M, Van Oosten VR, Van Poecke RMP, Van Pelt JA, Pozo MJ, Mueller MJ, Buchala AJ, Metraux JP, Van Loon LC, Dicke M, Pieterse CMJ (2005) Signal signature and transcriptome changes of Arabidopsis during pathogen and insect attack. Mol PlantMicrobe Interact 18:923-937

Engel P, Moran NA (2013) The gut microbiota of insects - diversity in structure and function. FEMS Microbiol Rev 37:699-735

Erb M, Meldau S, Howe GA (2012) Role of phytohormones in insectspecific plant reactions. Trends Plant Sci 17:250-259

Eriksson L, Johansson E, Kettaneh-Wold N, Trygg J, Wikström C, Wold S (2006) Multi- and megavariate data analysis. Part I: basic principles and applications. Umetrics Academy, Umeå 
Farmer EE, Ryan CA (1992) Octadecanoid precursors of jasmonic acid activate the synthesis of wound-inducible proteinase inhibitors. Plant Cell 4:129-134

Glawischnig E (2007) Camalexin. Phytochemistry 68:401-406

Glazebrook J (2005) Contrasting mechanisms of defense against biotrophic and necrotrophic pathogens. Annu Rev Phytopathol 43: 205-227

Guzman P, Ecker JR (1990) Exploiting the triple response of Arabidopsis to identify ethylene-related mutants. Plant Cell 6:513523

Halkier BA, Gershenzon J (2006) Biology and biochemistry of glucosinolates. Annu Rev Plant Biol 57:303-333

Hiruma K, Nishiuchi T, Kato T, Bednarek P, Okuno T, Schulze-Lefert P, Takano Y (2011) Arabidopsis ENHANCED DISEASE RESISTANCE 1 is required for pathogen-induced expression of plant defensins in nonhost resistance, and acts through interference of MYC2-mediated repressor function. Plant J 67:980-992

Howe GA, Jander G (2008) Plant immunity to insect herbivores. Annu Rev Plant Biol 59:41-66

Kazan K, Manners JM (2008) Jasmonate signaling: toward an integrated view. Plant Physiol 146:1459-1468

Kazan K, Manners JM (2013) MYC2: the master in action. Mol Plant 6: 686-703

Kessler A, Baldwin IT (2002) Plant responses to insect herbivory: the emerging molecular analysis. Annu Rev Plant Biol 53:299-328

Kettles GJ, Drurey C, Schoonbeek HJ, Maule AJ, Hogenhout SA (2013) Resistance of Arabidopsis thaliana to the green peach aphid, Myzus persicae, involves camalexin and is regulated by microRNAs. New Phytol 198:1178-1190

Kos M, Houshyani B, Wietsma R, Kabouw P, Vet LEM, Van Loon JJA, Dicke M (2012) Effects of glucosinolates on a generalist and specialist leaf-chewing herbivore and an associated parasitoid. Phytochemistry 77:162-170

Kusnierczyk A, Winge P, Jorstad TS, Troczynska J, Rossiter JT, Bones AM (2008) Towards global understanding of plant defence against aphids - timing and dynamics of early Arabidopsis defence responses to cabbage aphid (Brevicoryne brassicae) attack. Plant Cell Environ 31:1097-1115

Livak KJ, Schmittgen TD (2001) Analysis of relative gene expression data using real-time quantitative PCR and the 2 (T) (-Delta Delta C) method. Methods 25:402-408

Lorenzo O, Solano R (2005) Molecular players regulating the jasmonate signalling network. Curr Opin Plant Biol 8:532-540

Lorenzo O, Piqueras R, Sanchez-Serrano JJ, Solano R (2003) ETHYLENE RESPONSE FACTOR1 integrates signals from ethylene and jasmonate pathways in plant defense. Plant Cell 15:165-178

Mewis I, Tokuhisa JG, Schultz JC, Appel HM, Ulrichs C, Gershenzon J (2006) Gene expression and glucosinolate accumulation in Arabidopsis thaliana in response to generalist and specialist herbivores of different feeding guilds and the role of defense signaling pathways. Phytochemistry 67:2450-2462

Müller R, de Vos M, Sun JY, Sonderby IE, Halkier BA, Wittstock U, Jander G (2010) Differential effects of indole and aliphatic glucosinolates on lepidopteran herbivores. J Chem Ecol 36:905-913

Murashige T, Skoog F (1962) A revised medium for rapid growth and bio assays with tobacco tissue cultures. Physiol Plant 15:473-497

Pangesti N, Pineda A, Dicke M, Van Loon JJA (2015) Variation in plantmediated interactions between rhizobacteria and caterpillars: Potential role of soil composition. Plant Biol 17:474-483

Pieterse CMJ, VanWees SCM, Hoffland E, Van Pelt JA, Van Loon LC (1996) Systemic resistance in Arabidopsis induced by biocontrol bacteria is independent of salicylic acid accumulation and pathogenesis-related gene expression. Plant Cell 8:1225-1237

Pieterse CMJ, Van Wees SCM, Van Pelt JA, Knoester M, Laan R, Gerrits N, Weisbeek PJ, Van Loon LC (1998) A novel signaling pathway controlling induced systemic resistance in Arabidopsis. Plant Cell 10:1571-1580

Pieterse CMJ, Van Wees SCM, Ton J, Van Pelt JA, Van Loon LC (2002) Signalling in rhizobacteria-induced systemic resistance in Arabidopsis thaliana. Plant Biol 4:535-544

Pieterse CMJ, Van der Does D, Zamioudis C, Leon-Reyes A, Van Wees SCM (2012) Hormonal modulation of plant immunity. Annu Rev Cell Dev Biol 28:489-521

Pieterse CM, Zamioudis C, Berendsen RL, Weller DM, Van Wees SC, Bakker PA (2014) Induced systemic resistance by beneficial microbes. Annu Rev Phytopathol 52:347-375

Pineda A, Zheng SJ, Van Loon JJA, Pieterse CMJ, Dicke M (2010) Helping plants to deal with insects: the role of beneficial soilborne microbes. Trends Plant Sci 15:507-514

Pineda A, Zheng SJ, Van Loon JJA, Dicke M (2012) Rhizobacteria modify plant-aphid interactions: a case of induced systemic susceptibility. Plant Biol 14:83-90

Pozo MJ, Azcon-Aguilar C (2007) Unraveling mycorrhiza-induced resistance. Curr Opin Plant Biol 10:393-398

Pozo MJ, Van Der Ent S, Van Loon LC, Pieterse CMJ (2008) Transcription factor MYC2 is involved in priming for enhanced defense during rhizobacteria-induced systemic resistance in Arabidopsis thaliana. New Phytol 180:511-523

Pre M, Atallah M, Champion A, De Vos M, Pieterse CMJ, Memelink J (2008) The AP2/ERF domain transcription factor ORA59 integrates jasmonic acid and ethylene signals in plant defense. Plant Physiol 147:1347-1357

Prince DC, Drurey C, Zipfel C, Hogenhout SA (2014) The leucine-rich repeat receptor-like kinase BRASSINOSTEROID INSENSITIVE1ASSOCIATED KINASE 1 and the Cytochrome P450 PHYTOALEXIN DEFICIENT3 contribute to innate immunity to aphids in Arabidopsis. Plant Physiol 164:2207-2219

Raaijmakers JM, Leeman M, Van Oorschot MMP, Van der Sluis I, Schippers B, Bakker PAHM (1995) Dose-response relationships in biological control of Fusarium wilt of radish by Pseudomonas spp. Biol Control 85:1075-1081

Reymond P, Bodenhausen N, Van Poecke RMP, Krishnamurthy V, Dicke M, Farmer EE (2004) A conserved transcript pattern in response to a specialist and a generalist herbivore. Plant Cell 16:3132-3147

Schlaeppi K, Bodenhausen N, Buchala A, Mauch F, Reymond P (2008) The glutathione-deficient mutant pad2-1 accumulates lower amounts of glucosinolates and is more susceptible to the insect herbivore Spodoptera littoralis. Plant J 55:774-786

Schweizer F, Fernandez-Calvo P, Zander M, Diez-Diaz M, Fonseca S, Glauser G, Lewsey MG, Ecker JR, Solano R, Reymond P (2013) Arabidopsis basic helix-loop-helix transcription factors MYC2, MYC3, and MYC4 regulate glucosinolate biosynthesis, insect performance, and feeding behavior. Plant Cell 25:3117-3132

Selosse MA, Bessis A, Pozo MJ (2014) Microbial priming of plant and animal immunity: Symbionts as developmental signals. Trends Microbiol 22:607-613

Sels J, Mathys J, De Coninck BMA, Cammue BPA, De Bolle MFC (2008) Plant pathogenesis-related (PR) proteins: a focus on PR peptides. Plant Physiol Biochem 46:941-950

Shavit R, Ofek-Lalzar M, Burdman S, Morin S (2013) Inoculation of tomato plants with rhizobacteria enhances the performance of the phloem-feeding insect Bemisia tabaci. Front Plant Sci 4:306

Song YY, Ye M, Li CY, Wang RL, Wei XC, Luo SM, Sen Zeng R (2013) Priming of anti-herbivore defense in tomato by arbuscular mycorrhizal fungus and involvement of the jasmonate pathway. J Chem Ecol 39:1036-1044

Sugio A, Dubreuil G, Giron D, Simon JC (2014) Plant-insect interactions under bacterial influence: ecological implications and underlying mechanisms. J Exp Bot. doi:10.1093/jxb/eru435

Thomma BPHJ, Cammue BPA, Thevissen K (2002) Plant defensins. Planta 216:193-202 
Valenzuela-Soto JH, Estrada-Hernandez MG, Ibarra-Laclette E, Delano-Frier JP (2010) Inoculation of tomato plants (Solanum lycopersicum) with growth-promoting Bacillus subtilis retards whitefly Bemisia tabaci development. Planta 231:397-410

Van de Mortel JE, De Vos RCH, Dekkers E, Pineda A, Guillod L, Bouwmeester K, Van Loon JJA, Dicke M, Raaijmakers JM (2012) Metabolic and transcriptomic changes induced in Arabidopsis by the rhizobacterium Pseudomonas fluorescens SS101. Plant Physiol 160:2173-2188

Van der Ent S, Van Wees SCM, Pieterse CMJ (2009) Jasmonate signaling in plant interactions with resistance-inducing beneficial microbes. Phytochemistry 70:1581-1588

Van Oosten VR, Bodenhausen N, Reymond P, Van Pelt JA, Van Loon LC, Dicke M, Pieterse CMJ (2008) Differential effectiveness of microbially induced resistance against herbivorous insects in Arabidopsis. Mol Plant-Microbe Interact 21:919-930

Verhage A, Vlaardingerbroek I, Raaymakers C, Van Dam NM, Dicke M, Van Wees SCM, Pieterse CMJ (2011) Rewiring of the jasmonate signaling pathway in Arabidopsis during insect herbivory. Front Plant Sci 2:47
Verhagen BWM, Glazebrook J, Zhu T, Chang HS, van Loon LC, Pieterse CMJ (2004) The transcriptome of rhizobacteria-induced systemic resistance in Arabidopsis. Mol Plant-Microbe Interact 17:895-908

Von Malek B, Van der Graaff E, Schneitz K, Keller B (2002) The Arabidopsis male-sterile mutant dde2-2 is defective in the ALLENE OXIDE SYNTHASE gene encoding one of the key enzymes of the jasmonic acid biosynthesis pathway. Planta 216:187-192

Vos IA, Verhage A, Schuurink RC, Watt LG, Pieterse CMJ, Van Wees SCM (2013) Onset of herbivore-induced resistance in systemic tissue primed for jasmonate-dependent defenses is activated by abscisic acid. Front Plant Sci 4:539

Weston DJ, Pelletier DA, Morrell-Falvey JL, Tschaplinski TJ, Jawdy SS, Lu TY, Allen SM, Melton SJ, Martin MZ, Schadt CW, Karve AA, Chen JG, Yang X, Doktycz MJ, Tuskan GA (2012) Pseudomonas fluorescens induces strain-dependent and strain-independent host plant responses in defense networks, primary metabolism, photosynthesis, and fitness. Mol PlantMicrobe Interact 25:765-778

Zamioudis C, Pieterse CMJ (2012) Modulation of host immunity by beneficial microbes. Mol Plant-Microbe Interact 25:139-150 